Caras (os) colegas,

O número 10 da Revista da Sociedade Portuguesa de Enfermagem de Saúde Mental é editado em dezembro de 2013 e dá início a uma nova etapa, com a inclusão da revista na SciELO Citation Index - Thomson Reuters. Este passo era fundamental para aumentar o interesse e o impacte da revista na comunidade científica. Por isso, agradecemos a todos os que se empenharam e contribuíram para este resultado.

$O$ interesse na indexação representa muito para nós pelo facto de aumentarmos o público-alvo dos artigos que publicamos, e assim, divulgarmos os trabalhos de investigação e as práticas de qualidade por um maior número de colegas. Este é um contributo fundamental para a promoção da melhoria das práticas clinicas, da investigação e do ensino.

Em breve iremos editar uma edição especial com os trabalhos mais relevantes que foram apresentados no IV Congresso Internacional d' ASPESM, nos dias 10 e 11 de outubro na Escola Superior de Enfermagem de Coimbra.

Esta é uma metodologia que pretendemos adotar nos próximos eventos com o intuito de disseminarmos o conhecimento em Enfermagem de Saúde Mental por um maior número de profissionais de saúde.

Neste número da revista privilegiamos sete artigos de investigação que abordam:

i) Desinstitucionalizaçãode seniores com doença mental: A implementação de um modelo de transição e integração comunitária;

ii) Desenvolvimento de um catálogo CIPE: Necessidades do idoso em enfermagem de saúde mental e psiquiatria

iii) Estimulação cognitiva em idosos;

iv) Análise das atividades desenvolvidas por mulheres depressivas assistidas em um serviço de saúde mental;

v) Relaxamento: Estratégia de intervenção no stresse;

vi) O impacto do delirium na família / cuidadores;

vii) Promoção da saúde mental: Ações dos enfermeiros inseridos na atenção primária.
Reiteramos a todos os potenciais autores que continuamos muito interessados em publicar artigos sobre a adaptação cultural e análise de propriedades psicométricas de instrumentos para a população portuguesa, sobre resultados da efetividade de intervenções de Enfermagem, e sobre indicadores epidemiológicos e de resultado em Saúde Mental, quer seja em Portugal, quer seja no estrangeiro. Deixamos ainda a informação que entre 18 a 20 de junho de 2014 iremos realizar o V Congresso Internacional dedicado aos "Consensos em Saúde Mental” e o Seminário Internacional de Investigação em Saúde Mental.

O envio de propostas para Comunicação Oral/ Poster terá como prazo limite o dia 30 de abril de 2014.

Será editado um número especial da Revista Portuguesa de Enfermagem de Saúde Mental com os artigos que cumpram os critérios editoriais e científicos da revista. Os outros artigos poderão ser publicados em e-book.

Poderá consultar mais informações brevemente no site d' A Sociedade Portuguesa de Enfermagem de Saúde Mental, em www.aspesm.org.

\section{Prioridades da Investigação em Saúde Mental}

No contexto da Saúde Mental a investigação reveste-se de extrema importância, na medida em que concorrem múltiplas variáveis para a identificação rigorosa do diagnóstico e para a efetividade das Intervenções. Em Portugal, à semelhança de muitos países internacionais, carece-se de dados fiáveis sobre um conjunto de indicadores que traduzem a Saúde Mental das populações. Por outro lado, as verbas destinadas à investigação em Saúde Mental são muito diminutas face a outras áreas da saúde, em parte devido ao histórico da Saúde Mental, sustentada na luta contra a estigmatização que na maioria dos casos lhe é associada, e pela pouca valorização política por esta área de intervenção. Paradoxalmente, em termos de Enfermagem, verifica-se que muita da investigação produzida se situa nas áreas da Saúde Mental. No entanto, são escassos os trabalhos com implicações clinicas efetivas. 
Neste sentido, urge fazer um diagnóstico da situação de modo a orientar eventuais interessados nesta área a investirem em estudos com valor para a melhoria das práticas nos diferentes contextos de ação.

Por outro lado, importa reunir um conjunto de sinergias que privilegiem estudos multicêntricos, com metodologias similares e com amostra maiores, de modo a facilitar a transferência de informação da investigação para os contextos clínicos. É fundamental que as entidades académicas e de prestação de cuidados se articulem no sentido de otimizarem os recursos de investigação em prol de uma melhor saúde para os cidadãos, ao nível da promoção da Saúde Mental, prevenção da doença mental, e intervenção nas situações de doença diagnosticada. O contexto atual de contração económica é propício ao aumento do número de casos de depressão, risco de tentativa de suicídio e de consumo de substâncias psicoativas. Os progressos ao nível da saúde e a melhoria das condições socioeconómicas levam a que as pessoas vivam mais, o que contribui para o envelhecimento demográfico da população, o que é muito positivo, mas também acarreta um maior número das pessoas com um processo demencial.

Por isso, a investigação sobre as necessidades das pessoas com depressão e sobre as estratégias de intervenção com potencial terapêutico é fundamental para contrariar a tendência do elevado consumo de antidepressivos em Portugal. Do mesmo modo, a investigação sobre as necessidades das pessoas mais velhas poderá ser muito relevante para a adequação das respostas em saúde com implicações na qualidade de vida, na autonomia, na maximização da independência e na maior satisfação dos familiares cuidadores, contribuindo para que se viva mais e melhor.

Acreditando que a ignorância é mais dispendiosa que o conhecimento e na afirmação inscrita no Plano Nacional de Saúde Mental de 2007-2016, no qual se afirma que os dados de estudos de investigação em Saúde Mental em Portugal são escassos, consideramos fundamental sensibilizar os enfermeiros para a necessidade de produzirem trabalhos de investigação que possam contribuir para se dar resposta à seguinte questão:
Quais são as principais necessidades das pessoas (mais vulneráveis em termos de Saúde Mental e/ ou com doença mental) nos diferentes contextos ao longo do ciclo vital, e quais as respostas (intervenções de Enfermagem) mais efetivas, ou seja, que contribuem para a recuperação e reinserção das pessoas com doença mental, diminuindo os custos pessoais, familiares e sociais?

Esta questão transporta-nos objetivamente para a necessidade de se investigar sobre:

Indicadores epidemiológicos: quantas pessoas apresentam alteração da: memória, orientação, do comportamento, ansiedade, tristeza, vontade de viver, risco de tentativa de suicídio,...

Indicadores de estrutura: qual o número de enfermeiros que deve ter um determinado serviço, qual o rácio de enfermeiros por pessoa/doente; qual o rácio de enfermeiros especialistas; qual o tempo médio necessário para executar determinada intervenção,...

Indicadores de processo: quais os procedimentos mais adequados para determinado diagnóstico e intervenção; quais os instrumentos de referência a utilizar; quais as práticas que têm potencial de prevenção de determinados diagnósticos de Enfermagem, qual a taxa de prevenção de episódios de agitação, de agressividade, de risco de tentativa de suicídio,...

Indicadores de resultado: quais as intervenções que apresentam uma relação de custo-beneficio mais adequada. Estes indicadores possibilitam uma avaliação da efetividade das intervenções que possam dar resposta aos problemas da: literacia; bem-estar; cognição; memória; emoção; vontade de viver; adaptação; stress; ansiedade; autocontrolo; autoestima/imagem corporal; estilos de vida (álcool, drogas,...); autoagressão; comportamentos suicidários; sintomatologia depressiva;...

A investigação nestes quatro domínios permitirá aos enfermeiros fornecerem contributos efetivos para a criação de padrões de qualidade sustentados nas necessidades das pessoas e na eficácia das práticas clinicas.

A Investigação é muito importante para a profissão de Enfermagem e para as pessoas porque pode contribuir para: 
